\title{
Impacts of wind profile shear and curvature on the parameterized orographic gravity wave stress in the Weather Research and Forecasting model
}

Article

Accepted Version

Xu, X., Teixeira, M. A. C., Xue, M., Lu, Y. and Tang, J. (2020) Impacts of wind profile shear and curvature on the parameterized orographic gravity wave stress in the Weather Research and Forecasting model. Quarterly Journal of the Royal Meteorological Society, 146 (732). pp. 3086-3100. ISSN 1477-870X doi: https://doi.org/10.1002/qj.3828 Available at https://centaur.reading.ac.uk/90778/

It is advisable to refer to the publisher's version if you intend to cite from the work. See Guidance on citing.

To link to this article DOI: http://dx.doi.org/10.1002/qj.3828

Publisher: Royal Meteorological Society

All outputs in CentAUR are protected by Intellectual Property Rights law, including copyright law. Copyright and IPR is retained by the creators or other copyright holders. Terms and conditions for use of this material are defined in the End User Agreement. 


\section{www.reading.ac.uk/centaur}

\section{CentAUR}

Central Archive at the University of Reading

Reading's research outputs online 


\title{
Impacts of Wind Profile Shear and Curvature on the Parameterized Orographic
}

\section{Gravity Wave Stress in the Weather Research and Forecasting Model}

\author{
Xin $\mathrm{Xu}^{1}$, Miguel A. C. Teixeira ${ }^{2}$, Ming Xue ${ }^{1,3}$, Yixiong $\mathrm{Lu}^{4}$, and Jianping Tang ${ }^{1}$ \\ ${ }^{1}$ Key Laboratory of Mesoscale Severe Weather/Ministry of Education, and School of Atmospheric \\ Sciences, Nanjing University, Nanjing 210023, Jiangsu, P. R. China \\ ${ }^{2}$ Department of Meteorology, University of Reading, Earley Gate, PO Box 243, Reading RG6 6BB, UK \\ ${ }^{3}$ Center for Analysis and Prediction of Storms, and School of Meteorology, University of Oklahoma, \\ Norman, OK 73072, USA \\ ${ }^{4}$ Beijing Climate Center, China Meteorological Administration, Beijing 100081, P. R. China
}

Submitted to Quart. J. Roy. Meteor. Soc.

31 March 2020

Corresponding author

$\mathrm{Xin} \mathrm{Xu}$

School of Atmospheric Sciences, Nanjing University

No. 163, Xianlin Avenue, Nanjing, Jiangsu, 210023, P. R. China

Email: xinxu@nju.edu.cn

\begin{abstract}
The parameterization of orographic gravity wave drag (OGWD) in the Weather Research and Forecasting model is extended by including the second-order Wentzel-Kramers-Brillouin (WKB) corrections to the surface wave momentum flux (SWMF) caused by wind profile shear (WSHR) and curvature (WCUR) effects. Simulations of the atmospheric circulation are performed to study the behavior and impact of WKB corrections. In January, the SWMF is weakened in the Northern Hemisphere $(\mathrm{NH})$ midlatitudes by the WSHR term while WCUR acts to enhance the SWMF over Antarctica. In July, the WSHR corrections are similar to those in
\end{abstract}

This article has been accepted for publication and undergone full peer review but has not been through the copyediting, typesetting, pagination and proofreading process which may lead to differences between this version and the Version of Record. Please cite this article as doi: $10.1002 / q j .3828$ 
January whereas the WCUR term produces corrections of opposite sign in the high latitudes of each hemisphere. The latter is attributed to the increase of near-surface winds in the cold season which reverses the low-level wind profile curvature. The seasonal reversal of the WCUR term contradicts previous findings obtained from offline evaluation using reanalysis datasets. This may be due to the different OGWD parameterization schemes used, or suggest a sensitivity to the height where the wind profiles effects are evaluated. Changes in the SWMF can affect the vertical distribution of parameterized OGWD. In January, the OGWD in the NH midlatitudes is decreased in the lower troposphere but increased in the upper troposphere. This is because a reduced SWMF inhibits wave breaking in the lower troposphere. Therefore, more WMF is transported to the upper troposphere which enhances wave breaking there. The increased uppertropospheric wave breaking in turn decreases the WMF propagating into the stratosphere where the OGWD is reduced. In July, the reduction of SWMF over Antarctica is more notable than that in the $\mathrm{NH}$ midlatitudes in January. Consequently, the OGWD is weakened in the upper troposphere over Antarctica.

Keywords: orography; gravity waves; parameterization; wind profile effects; WKB approximation 


\section{Introduction}

It has been widely recognized that the momentum transport by orographic gravity waves (OGWs) greatly affects the general circulation, especially in the middle atmosphere (e.g., Alexander et al. 2010). In general circulation models, the transport and deposition of momentum by OGWs are treated via the parameterization of OGW drag (OGWD; Kim et al. 2003) because of the small horizontal scales of OGWs compared to the model grid spacing, i.e., the OGWs are of subgrid scale. Parameterizations of OGWD have been developed since the 1980s, and necessary improvements continue to take place. Essentially, an OGWD parameterization scheme (i) calculates the wave momentum flux (WMF) at the surface (i.e., wave generation) and (ii) handles the vertical propagation and dissipation of OGWs defining the WMF profile.

The surface WMF (hereafter, SWMF) plays a key role in the parameterization of OGWD because it governs the total subgrid-scale orographic (SGSO) forcing in the model. In the first OGWD parameterizations, the SWMF was calculated using the analytical solution of linear gravity waves forced by sinusoidal orography (e.g., Palmer et al. 1986; McFarlane 1987). Since then, many efforts have been made to improve the accuracy of the SWMF formulation. According to high-resolution numerical simulations, the SWMF of nonlinear gravity waves forced by large-amplitude mountains could be much larger than that predicted by linear gravity wave theory, in situations which are known as "high-drag states" (Miranda and James 1992). This nonlinear enhancement was accounted for in the parameterization scheme developed by Kim and Arakawa (1995, hereafter KA95), which was validated against mesoscale numerical simulations. Following Phillips (1984), Lott and Miller (1997, hereafter LM97) adopted the analytical solution of gravity waves generated by three-dimensional (3D) orography with an elliptical horizontal cross-section in their parametrization scheme, rather than using the simple 
two-dimensional (2D) sinusoidal terrain of earlier studies. KA95 had also considered the effect of the shape of isolated orography (i.e., orographic asymmetry and convexity), but only in a 2D framework. Kim and Doyle (2005, hereafter KD05) extended the KA95 scheme to 3D conditions by incorporating the effect of orographic anisotropy.

The analytical solution of OGWs employed in LM97 and other parameterization schemes was derived under the assumption of constant flow over topography (e.g., Smith 1980; Phillips 1984). Using linear gravity wave theory, Grubisisić and Smolarkiewicz (1997) and Xu et al. (2012, 2017a) derived analytical formulae for the SWMF for linearly sheared airflow over circular bellshaped mountains. Their results revealed that, in the presence of vertical wind shear, the SWMF was weaker than in the constant-flow case. Based upon a second-order Wentzel-KramersBrillouin (WKB) approximation, Teixeira et al. (2004) developed an analytic model which accounted for the effects of both wind profile shear and curvature on the SWMF. In the case of hydrostatic flow over an isolated axisymmetric mountain, the SWMF was shown to decrease as the mean-flow Richardson number (Ri) decreases for a linearly sheared wind profile (in agreement with the exact results mentioned above); yet the SWMF was shown instead to be amplified above its zero-shear value as Ri decreases for a wind profile that rotates with height at a constant wind speed. This analytic model was also extended to cases of gravity waves forced by 2D ridges and 3D elliptical mountains (Teixeira and Miranda 2004, 2006).

Miranda et al. (2009, hereafter M09) firstly assessed the impacts of wind profile shear and curvature on the global atmospheric torque by applying their analytical model to the ERA-40 reanalysis data and performing an offline evaluation. The overall effect was to reduce the global westerly OGWD torque. However, significant drag enhancement of up to $50 \%$ occurred over Antarctica and East Africa, suggesting the dominance of wind profile curvature over the shear 
effect (which tends to reduce the drag) in those regions. Recently, Turner et al. (2019, hereafter T19) further examined the sensitivity of SWMF to the wind profile shear and curvature over Antarctica using the same method. The effects were evaluated at two different levels, i.e., at the top of the planetary boundary layer and at a height of the order of the standard deviation of the SGSO elevation, for both isotropic and anisotropic orography. The results showed that the effects were qualitatively robust to changes in the height where they were evaluated. Drag enhancement was found over Antarctica, especially in austral winter. This confirmed the important and dominant role of wind profile curvature (relative to linear shear) over Antarctica, found by M09.

Although OGWD parameterization has long been adopted in numerical weather prediction and climate models, the effects of wind profile shear and curvature on the SWMF have not been considered in any operational OGWD scheme. In a recent study by Xu et al. (2019, hereafter X19), the OGWD parameterization scheme in the Weather Research and Forecasting (WRF) model was extended by including the directional absorption (or selective critical level filtering; e.g., Shutts 1995; Xu et al. 2018) of OGWs associated with directional wind shear. X19 only considered the propagation and dissipation of OGWs within the atmosphere but not their generation. This study aims to further extend the OGWD scheme by considering the impacts of wind profile shear and curvature on the SWMF. The main purpose is to study the features of wind profile effects (i.e., changes to SWMF induced by wind profile shear and curvature) focusing on the different impacts on the SWMF magnitude (enhancement or reduction) they may have. The wind fields used in the offline studies of M09 and T19 were from reanalysis datasets, and thus were affected by the OGWD scheme adopted in the model. In this regard, wind profile effects need to be re-examined in a more consistent framework by performing simulations with 
an OGWD parameterization scheme that itself includes these effects. Moreover, the changes in the SWMF can also affect the vertical distribution of OGWD, an aspect which has not been examined before.

The rest of this paper is organized as follows. Section 2 firstly introduces and extends the OGWD scheme in the WRF model and then describes the setup of numerical simulations. The impacts of wind profile shear and curvature on the SWMF and the vertical distribution of OGWD are analyzed in section 3 . The paper is summarized in section 4, along with further discussion.

\section{Methodology}

\subsection{OGWD parameterization scheme in WRF}

The OGWD scheme in the WRF model was developed by KD05, accounting for various aspects of the SGSO, e.g., orographic asymmetry (OA), orographic convexity (OC) and effective orographic length $\left(L_{x}\right)$. Note that $L_{x}$ is defined along the direction of low-level mean wind $\mathbf{V}_{L}$ (see below). For gravity waves forced by the SGSO, the WMF at the reference level (i.e., the level at which the OGWs are generated) is the SWMF. In the WRF model, the reference level is set to the maximum of either: $2 \sigma_{h}$ above the model surface or the planetary boundary layer (PBL) height (Hong et al. 2008), with $\sigma_{h}$ being the standard deviation of the SGSO height. This definition has a certain degree of arbitrariness, but may be used for a number of purposes, including defining the height where the wind profile effects that are the focus of the present study are estimated (see below). The underlying assumption is that the pressure contribution from these inviscid effects is transmitted with little change across the PBL. The SWMF is given by 


$$
\begin{gathered}
\tau_{\text {ref }}=\rho_{0} E \frac{m}{\lambda_{e f f}} G \frac{\left|\mathbf{V}_{L}\right|^{3}}{N} \\
E=(O A+2)^{C E_{E} \frac{F r_{0}}{F r_{C}}}, m=\left(1+L_{x}\right)^{O A+1}, G=\frac{F r_{0}^{2}}{F r_{0}^{2}+C_{G} \mathrm{OC}^{-1}}, F r_{0}=\frac{2 \sigma_{h} N}{\left|\mathbf{V}_{L}\right|} O D .
\end{gathered}
$$

Here, the factor $E$ accounts for the effect of drag enhancement by low-level wave breaking and/or lee wave trapping, while factor $G$ provides a smooth transition between blocking and nonblocking flows determined using a critical Froude number of $F r_{c}=1$. The two constants $C_{E}=0.8$ and $C_{G}=0.5$ are obtained empirically from the mesoscale numerical simulations of KA95. $m$ denotes the number of SGSO elements within the model grid cell and $\lambda_{\text {eff }}$ is the effective grid length. $\rho_{0}, \mathbf{V}_{L}$ and $N$ are the low-level air density, wind velocity and Brunt-Väisälä frequency averaged between the surface and $2 \sigma_{h}$ above the surface. $O D=\frac{L_{x}^{\frac{1}{x}}}{L_{x}}$ is the orographic direction quantifying the SGSO anisotropy, with $L_{x}^{\perp}$ being the effective orography length normal to $L_{x}$ (i.e., normal to the low-level wind).

In the model, the reference-level WMF is propagated upward level by level. At each model level, flow instability is checked in accordance with the wave saturation hypothesis (Lindzen 1981). In the event of wave saturation, OGWs will break and exert a body force on the mean flow through the deposition of wave momentum, i.e.,

$$
\frac{d \mathbf{V}(\mathbf{z})}{d t}=\frac{1}{\rho(z)} \frac{\partial \tau(z)}{\partial z}
$$

where $\mathbf{V}(z)$ and $\boldsymbol{\tau}(z)$ are the mean flow velocity and WMF vectors at height $z$, respectively. Note that the direction of $\boldsymbol{\tau}(z)$ is parallel to the mean flow at the low level (i.e., $\mathbf{V}_{L}$ ). The remaining WMF continues to propagate upward until OGWs are completely absorbed by the mean flow or reach the model top. 


\subsection{Revision of the KD05 scheme}

Using a second-order WKB approximation, Teixeira and Miranda (2006, hereafter TM06) derived analytical expressions for the corrections to the $\operatorname{SWMF}\left(D_{x}, D_{y}\right)$ due to wind profile shear and curvature (their Eqs. (31) and (32)):

$$
\begin{aligned}
& \frac{D_{x}}{D_{0 x}}=1-\frac{1}{8}\left\{\alpha\left(\frac{U_{0}^{\prime 2}}{N^{2}}+2 \frac{U_{0} U_{0}^{\prime \prime}}{N^{2}}\right)+(1-\alpha)\left(\frac{V_{0}^{\prime 2}}{N^{2}}+2 \frac{V_{0}}{U_{0}} \frac{U_{0}^{\prime} V_{0}^{\prime}}{N^{2}}+2 \frac{V_{0}}{U_{0}} \frac{U_{0}^{\prime \prime} V_{0}}{N^{2}}+4 \frac{V_{0}^{\prime \prime} V_{0}}{N^{2}}\right)\right\}, \\
& \frac{D_{y}}{D_{0 y}}=1-\frac{1}{8}\left\{\beta\left(\frac{V_{0}^{\prime 2}}{N^{2}}+2 \frac{V_{0} V_{0}^{\prime \prime}}{N^{2}}\right)+(1-\beta)\left(\frac{U_{0}^{\prime 2}}{N^{2}}+2 \frac{U_{0}}{V_{0}} \frac{U_{0}^{\prime} V_{0}^{\prime}}{N^{2}}+2 \frac{U_{0}}{V_{0}} \frac{V_{0}^{\prime \prime} U_{0}}{N^{2}}+4 \frac{U_{0}^{\prime \prime} U_{0}}{N^{2}}\right)\right\},
\end{aligned}
$$

where $\left(D_{0 x}, D_{0 y}\right)$ is the SWMF calculated assuming a constant flow, and $\left(U_{0}, V_{0}\right)$ is the horizontal wind at the surface, with $\left(U_{0}^{\prime}, V_{0}^{\prime}\right)$ and $\left(U_{0}^{\prime \prime}, V_{0}^{\prime \prime}\right)$ being the wind profile shear and curvature, respectively. By "surface", here we mean a level where the shear and curvature in the wind profile affect most the SWMF. It is not a priori obvious what this height should be, but it is plausible that it is not too high above the ground (otherwise its contribution to the surface pressure would be negligible), nor as low as to be inside the PBL, because the theory used to derive (4)-(5) is inviscid (and pressure fluctuations are known to be transmitted with relatively small modifications across thin boundary layers). The coefficients $\alpha$ and $\beta$ depend on the mountain anisotropy. In the case of an elliptical bell-shaped mountain, i.e.,

$$
h(x, y)=\frac{h_{m}}{\left[1+(x / a)^{2}+(y / b)^{2}\right]^{3 / 2}}
$$

with $a$ and $b$ as the mountain half-widths along its main axes and $h_{m}$ the mountain amplitude. $\alpha$ and $\beta$ take the following form (Eqs. (33) and (34) in TM06),

$$
\begin{aligned}
& \alpha(\gamma)=\frac{I_{1}(\gamma)}{B(\gamma)}=1-\frac{I_{2}(\gamma)}{B(\gamma)}=\frac{1}{1-\gamma^{2}}\left\{1-\frac{C(\gamma)}{B(\gamma)}\right\}, \\
& \beta(\gamma)=\frac{\gamma I_{1}(1 / \gamma)}{C(\gamma)}=1-\frac{\gamma I_{2}(1 / \gamma)}{C(\gamma)}=\frac{\gamma^{2}}{1-\gamma^{2}}\left\{\frac{B(\gamma)}{C(\gamma)}-1\right\},
\end{aligned}
$$


where $\gamma=a / b$ is the horizontal aspect ratio of the elliptical mountain, and

$$
\begin{gathered}
B(\gamma)=\int_{0}^{\pi / 2} \frac{\cos ^{2} \theta}{\left(\cos ^{2} \theta+\gamma^{2} \sin ^{2} \theta\right)^{1 / 2}} d \theta, \quad C(\gamma)=\gamma^{2} \int_{0}^{\pi / 2} \frac{\sin ^{2} \theta}{\left(\cos ^{2} \theta+\gamma^{2} \sin ^{2} \theta\right)^{1 / 2}} d \theta, \\
I_{1}(\gamma)=\int_{0}^{\pi / 2} \frac{\cos ^{4} \theta}{\left(\cos ^{2} \theta+\gamma^{2} \sin ^{2} \theta\right)^{1 / 2}} d \theta, \quad I_{2}(\gamma)=\gamma^{2} \int_{0}^{\pi / 2} \frac{\cos ^{2} \theta \sin ^{2} \theta}{\left(\cos ^{2} \theta+\gamma^{2} \sin ^{2} \theta\right)^{1 / 2}} d \theta,
\end{gathered}
$$

which are Eqs. (21)-(22) and (27)-(28) in TM06. It can be easily verified that $\alpha(\gamma)=\beta(1 / \gamma)$, and $\alpha=\beta=3 / 4$ for an axisymmetric mountain (i.e., $\gamma=1$ ). Figure 1 shows the variation of $\alpha(\gamma)$ with the terrain anisotropy, which approaches unity at $\gamma=1 / 10$ and decreases to about 0.36 at $\gamma=10$.

As noted above, in the KD05 scheme the effective orography lengths (namely, $L_{x}$ and $L_{x}^{\perp}$ ) of the assumed SGSO are defined in the directions along and perpendicular to the low-level mean wind respectively (see Fig. 7 in KD05 and Fig. 1 in X19). For lack of more complete information about the orography, the best choice consistent with this assumption in the framework of TM06 is taking $L_{x}$ and $L_{x}^{\perp}$ as the mountain widths along the main axes of the elliptic orography, as if the low-level wind was aligned with one of those axes. In this simple case, to account for the effects of wind profile shear and curvature, the reference-level WMF for the KD05 scheme is simplified to

$$
\tilde{\tau}_{\text {ref }}=\tau_{\text {ref }}\left[1-\frac{\alpha}{8}\left(\frac{U_{L}^{\prime 2}}{N^{2}}+2 \frac{U_{L} U_{L}^{\prime \prime}}{N^{2}}\right)\right]=\tau_{\text {ref }}\left[1-\frac{\alpha}{8}\left(\frac{1}{R i}+2 \frac{U_{L} U_{L}^{\prime \prime}}{N^{2}}\right)\right]
$$

where $U_{L}=U_{L}(z)$ is the wind component in the direction of the low-level mean wind $\mathbf{V}_{L}$. In deriving the above equation, the wind component orthogonal to the low-level mean wind and its vertical derivatives are omitted. This is consistent with the unidirectional wind assumption adopted for the SWMF in the KD05 scheme. This assumption is also adopted in a number of other OGWD parameterization schemes, e.g., the LM97 scheme (although in this scheme the flow may be oblique to the main axes of the orography). The first term inside the parenthesis on 
the right-hand-side (RHS) of Eq. (11) represents the second-order WKB correction due to wind profile shear (hereafter, WSHR term). It is always negative and inversely proportional to $R i$. The second term accounts for the effect of wind profile curvature (hereafter, WCUR term). Unlike the WSHR term, there is no a priori indication for the sign of the WCUR term.

For the implementation of the revised OGWD scheme in the WRF model, the first and second derivatives of $U_{L}(z)$ at the reference level are calculated using centered finite differences at three consecutive model levels, i.e., the reference level and the levels below and above it. As shown in Teixeira et al. (2004) and TM06, the second-order WKB corrections are formally valid for $R i$ as low as 0.5 , while it is known that dynamic/static instabilities can occur when $R i$ falls below 0.25 . Hence the WKB corrections are only applied at grid points where $R i$ is greater than 0.5. Furthermore, since the wind profile effects (as formulated here) change the magnitude of the SWMF rather than its direction, the WKB corrections are limited to be higher than -1 relative to the original SWMF value, so that the SWMF does not change sign. If this occurred, the WKB correction would be of questionable validity anyway, since due to its asymptotic nature it is supposed to be smaller than the SWMF value it corrects.

\subsection{Numerical simulations}

As in X19, numerical simulations are performed using the global version of the WRF model (GWRF), which is an extension of the mesoscale version of WRF and a variant of Planet WRF (Richardson et al. 2007). The model uses a latitude-longitude grid, with a Fourier spectral filter applied in the polar regions to prevent numerical instability near the poles. To study wind profile effects, two sets of free-running numerical simulations are conducted using the KD05 scheme (OLD experiment) and the revised scheme (NEW experiment) respectively. In each set, there are 20 one-month simulations, with 10 in January and 10 in July of 2009-2018, respectively. 
Note that to focus exclusively on the effects of the modified SWMF, the modifications made by X19 to the propagation of OGWs due to directional wind shear are not included herein.

The horizontal resolution of the GWRF model is set to $1^{\circ} \times 1^{\circ}$, with 41 levels in the vertical. The model top is located at $10 \mathrm{hPa}$, because the model's initial conditions are derived from the $1^{\circ} \times 1^{\circ}$ Global Forecast System (GFS) analyses, which are limited to $10 \mathrm{hPa}$ in the vertical. A sponge layer is employed in the uppermost $5 \mathrm{~km}$ of the model to damp waves reflected from the top of the domain. A number of parameterization schemes are used for model physics, e.g., the WRF single-moment 3-class microphysical scheme (Hong et al. 2004), the RRTMG longwave and shortwave radiation schemes (Iacono et al. 2008), the Yonsei University (YSU) PBL scheme (Hong et al. 2006), the MM5 similarity scheme for the surface layer (Beljaars 1994), the new Tiedtke scheme for cumulus convection (Zhang et al. 2011) and the Noah land surface model (Tewari et al. 2004).

\section{Results}

\subsection{General features of simulated WKB corrections}

The zonal-mean SWMF in experiment OLD is shown in Fig. 2. In January, the largest SWMF occurs in the midlatitudes of the Northern Hemisphere $(\mathrm{NH})$, where the SGSO is most remarkable. Two other peaks of SWMF also appear in the high latitudes of the $\mathrm{NH}$, due to the local SGSO maxima existing there. In the Southern Hemisphere (SH), the SWMF is much weaker except in the polar region, where the SGSO is comparable to that in the midlatitudes of the NH. In July, the SWMF decreases markedly in the NH mid and high latitudes, but increases dramatically over Antarctica. The differences between the SWMF in January and July are mainly 
due to the fact that the horizontal wind is weaker in summer than in winter in each hemisphere. According to Eq. (1), the SWMF is increased as the horizontal wind speed increases.

In experiment NEW, the zonal-mean SWMF is similar to that in OLD, because the zonalmean corrections due to the wind profile shear and curvature are relatively small. Figure 3 displays the zonal-mean WKB correction terms to the SWMF (i.e., terms in the square brackets in Eq. (11)) in experiment NEW. In January (Fig. 3a), the WKB corrections due to wind profile shear (i.e., WSHR) are negative, with notable corrections found over Antarctica and between about $30^{\circ} \mathrm{S}$ and $60^{\circ} \mathrm{N}$. By contrast, the wind profile curvature (WCUR) generally induces positive corrections except in the high latitudes of the NH. Overall, the WSHR term is dominated by WCUR in the SH (especially over Antarctica), giving rise to an enhancement of the SWMF there. This is consistent with the results of M09 and T19. In the NH, however, the SWMF is predominantly reduced owing to the more negative WSHR term.

Although the zonal-mean WKB corrections only account for about $1 \%$ of the SWMF, they show large spatial variability. In localized regions the corrections can reach values as high as about $30 \%$, i.e. they are of the same order of magnitude as those of M09. Figure 4a shows the spatial distribution of the total WKB corrections in January, with the WSHR and WCUR terms presented in Figs. 4c and 4e, respectively. Negative WKB corrections mainly occur in western North America, southwestern Greenland, and in a vast region extending from southern Europe to East Asia (Fig. 4a). Conversely, the total WKB corrections are positive in eastern South America, southern Africa, northwestern Australia and in parts of Antarctica. Regarding the WSHR term (Fig. 4c), notable corrections are found between $45^{\circ} \mathrm{S}$ and $45^{\circ} \mathrm{N}$, especially in East Asia, western North America, southern South America, and southern and eastern Africa. The WCUR term is positive almost everywhere, with salient corrections found in southern Africa, eastern South 
America, and Antarctica (Fig. 4e). However, there are still negative corrections due to the WCUR term over the Tibetan Plateau (TP), southwestern Greenland and in parts of the northern Rocky Mountains. As a consequence, these regions are characterized by important negative total WKB corrections (Fig. 4a).

In July, the zonal-mean WKB corrections differ markedly from those in January (Fig. 3b). In the high latitudes of the $\mathrm{NH}$, although the WSHR term becomes more negative than in January, the positive WCUR term increases more notably there, leading to a net enhancement of SWMF. In the high latitudes of the SH, the WCUR term changes to negative, which adds to the salient reduction of SWMF by the WSHR term. Moreover, the WCUR term is found to increase notably in the NH subtropical region. The two terms are hardly changed at other latitudes, however.

The spatial distributions of the total WKB correction, WSHR and WCUR terms in July are shown in Figs. 4b, 4d, and 4f, respectively. Compared to January, the total WKB corrections change to negative (positive) in Antarctica (Greenland), which is mainly attributed to the seasonal reversal of the WCUR term (see below). The WSHR term (Fig. 4d) is strengthened, that is, it becomes more negative over the northern North America and Eurasia. Meanwhile, the WCUR term increases over northern Eurasia and in the lower latitudes of the NH (e.g., western India, Fig. 4f). In particular, the WCUR term changes from negative (positive) to positive (negative) in Greenland (Antarctica), giving rise to the seasonal reversal of the total WKB correction there. Similarly, over the TP, the WCUR term changes from largely negative in January to slightly positive in July. In consequence, the total WKB corrections are significantly reduced in July (Fig. 4b). This seasonal reversal of the WCUR drag correction (and consequently of the total drag correction) is at odds with the findings of M09 and T19, so it deserves a more detailed analysis. 


\subsection{Seasonal variation of WCUR}

In January and July, the WCUR term at high latitudes (i.e., Antarctica and Greenland) and over the TP has different signs. According to Eq. (11), the WCUR term is positive when the sign of the wind profile curvature is opposite to that of the low-level mean flow. Figures 5a and $5 \mathrm{~b}$ show the horizontal wind at the first model level above the ground in the SH polar region. In July (i.e., austral winter), the near-surface winds over Antarctica are notably increased compared to those in January (i.e., austral summer), especially in the mountainous regions. These strong near-surface winds, known as katabatic winds, are one of the most common meteorological features over Antarctica (Parish and Bromwich 1991). As shown below, the enhanced nearsurface winds may not only lead to an increase of the SWMF (Fig. 2) but may also contribute to decrease the SWMF, depending on the sign of the wind profile curvature at the reference-level height.

Figure 6a illustrates the vertical profile of the horizontal wind averaged over eastern Antarctica (see Figs. 4e, f). Note that before taking the area average, the horizontal wind profile is projected onto the direction of the low-level mean wind at each model grid. Given the high wind speed near the surface, the vertical shear is notably increased (i.e., more negative) below the reference level, producing a positive vertical curvature at the reference level. Therefore, the WCUR term becomes negative in July. This can also explain the seasonal reversal of the WCUR

term in Greenland, where the near-surface winds are increased in January (Figs. 5c, 5d). High winds occurring in winter over Greenland have been widely reported (e.g., Moore and Renfrew 2005; Oltmanns et al. 2014). Note that the even stronger wind shear/curvature that exist below the reference level in Fig. 5 do not affect the SWMF because in the OGWD scheme the airflow 
is assumed to be blocked below the reference level, with the OGWs only being generated above that level.

The seasonal reversal of the WCUR term over the TP, on the other hand, is caused by the variation of the subtropical jet in the upper troposphere. Figure $6 \mathrm{~b}$ is akin to Fig. 6a, but presents the wind profile averaged over the TP. In January, there is a westerly jet located in the upper troposphere near $250 \mathrm{hPa}$, which produces a stronger vertical shear above the reference level than below it. As a result, the wind profile curvature is positive at the reference level, giving rise to negative WCUR. This westerly jet is actually part of the subtropical jet existing in the NH mid-to-low latitudes in winter (Fig. 7a). In July (Fig. 7c), the TP (indicated by the box) is on the northern flank of a large-scale anticyclone associated with the South Asian High (SAH) in the upper troposphere and lower stratosphere. The weakening of the upper-level jet reverses the wind profile curvature at the reference level, giving rise to the slightly positive WCUR term found in July (Fig. 4f).

The enhancement of the WCUR term in the low latitudes of the NH in July is also briefly analyzed next. Taking western India as an example, a low-level jet is formed at the level of about $900 \mathrm{hPa}$ in July, which increases the wind profile curvature at the reference level (Fig. 6c). This low-level jet is associated with the southwesterly monsoonal flow originating from the SH (Fig. 7d). In January (Fig. 7b), the monsoonal flows are much weaker than those in July and blow from the interior of the Asian continent. Nonetheless, the WCUR term over western India is not reversed between the two seasons, which is different from what happens in the polar regions and the TP.

While this reversal of the sign of the WCUR may be understood as an artefact of the level where the wind profile corrections to the drag are evaluated, its mere existence is important, 
because it contradicts the idea, advocated by M09 and T19, that the sign of the drag corrections is robust with respect to the choice of this level. In M09 and T19, the WCUR term was shown to be overwhelmingly positive over Antarctica, with no seasonal reversal as found in the present study. This difference might be attributed to the following reasons. Firstly, in M09 and T19, the wind profile effects were evaluated offline using reanalysis datasets (ERA-40 and ERA-Interim), the vertical resolution of which may be too coarse to capture the seasonal reversal of the wind profile curvature accurately. Secondly, the levels at which the WKB corrections were estimated in M09 and T19 differ from those adopted herein. It is not immediately obvious which choice is the best one, but the present results suggest a sensitivity to these levels (see Fig. 6), which is important enough to reverse the sign of the total correction to the SWMF. Thirdly, the WKB corrections depend on the terrain anisotropy (see the coefficients $\alpha$ and $\beta$ in Eqs. (4), (5) and (11)). In M09 and T19, this anisotropy was calculated following the LM97 scheme, which differs from the KD05 scheme employed herein. Lastly (and relatedly), M09 and T19 used the fully 3D version of the WKB corrections, while the reduced 2D version given by (11) was used here.

\subsection{Influence on the vertical distribution of OGWD}

Changes in the WMF at the surface can affect the height where OGWs break and hence the vertical distribution of OGWD. Figure 8 separately presents the zonal-mean zonal OGWD in the OLD and NEW experiments as well as their differences. In January, the most prominent OGWD is located above the NH subtropical jet (Figs. 8a, 8c), consistent with previous studies (e.g., Xu et al. 2017b; X19). Westward OGWD is also found in the lower troposphere between about $30^{\circ} \mathrm{N}$ and $50^{\circ} \mathrm{N}$, although it is weaker than at upper levels. In the $\mathrm{SH}$, however, there is little OGWD at high altitudes (not shown). This is because the SWMF is very weak in the mid and low latitudes of the $\mathrm{SH}$ in this season (Fig. 2). In the high latitudes, although there is 
noticeable SWMF over Antarctica, OGWs are prone to break in the lower troposphere rather than at upper levels. This is owing to the reversal of zonal wind at about $600 \mathrm{hPa}$, with easterlies below and westerlies above this level (not shown). This horizontal wind reversal forms a critical level for vertically propagating OGWs. The difference between the OGWD in the OLD and NEW experiments (NEW minus OLD) is shown in Fig. 8e. Compared to that in OLD, the OGWD in the NEW experiment is reduced in the lower troposphere and stratosphere, but enhanced in the upper troposphere of NH midlatitudes.

In July (Figs. 8b, 8d), the OGWD is notably enhanced in the lower and upper troposphere over Antarctica, which is consistent with the increase of the SWMF occurring there (Fig. 2). Compared to the OLD experiment, the NEW experiment shows weaker OGWD between about 300 and $100 \mathrm{hPa}$ in the upper troposphere over Antarctica (Fig. 8f). Contrastingly, the differences between the OGWD in the two experiments are very small in the NH. In fact, the OGWD in the midlatitudes of the NH is greatly reduced in July, almost vanishing (not shown). This can be partly ascribed to a weakening of the SWMF, which corresponds to about $40 \%$ of that existing in January around $45^{\circ} \mathrm{N}$ (Fig. 2). Given the even greater seasonal variation of the OGWD in the midlatitudes of the NH, the weaker vertical wind shear above the NH subtropical jet core in July compared to that in January may also contribute to a reduction of the OGWD.

Differences between the OGWD in the OLD and NEW experiments, which are attributable to the WKB corrections caused by wind profile shear and curvature, may be interpreted in the following way. As shown in Fig. 3a, the zonal-mean SWMF is reduced in the midlatitudes of the NH in January. Figure 9a displays the vertical profile of normalized WMF averaged between $30^{\circ} \mathrm{N}$ and $50^{\circ} \mathrm{N}$ in January. The normalization is made using the SWMF in experiment OLD. In NEW, the SWMF is weakened by about $2 \%$ compared to its value in OLD, 
which indicates OGWs of smaller amplitude. Therefore, gravity wave breaking is inhibited in the lower troposphere, leading to smaller OGWD there (Fig. 8e). Owing to the suppression of lowlevel wave breaking, OGWs can transport more WMF to the upper troposphere, as evidenced by the larger WMF between about $700 \mathrm{hPa}$ and $150 \mathrm{hPa}$ in the NEW experiment. The increased amount of WMF originating from below favors wave breaking in the upper troposphere, where more WMF is deposited into the mean flow, thus producing a stronger OGWD there (Fig. 8e). Higher up, the stratospheric OGWD weakens (Fig. 8e), given the fewer OGWs that are left and can propagate into the stratosphere (see in Fig. 9a the smaller WMF above $100 \mathrm{hPa}$ in NEW). This kind of change to the OGWD is qualitatively similar to that predicted in X19; however, in that study it was caused by the directional absorption of OGWs, which is a totally different physical process. Moreover, changes in the mean flow caused by the changes in the propagation and breaking of resolved waves (e.g., Rossby waves) may also give a contribution to the changes in stratospheric OGWD in midlatitudes (e.g., Cohen et al. 2013; Sigmond and Shepherd 2014; Sandu et al. 2016). However, the interaction between the resolved and parameterized waves, as well as between the resolved waves and the mean flow, is beyond the scope of this work.

Figure $9 \mathrm{~b}$ illustrates the vertical profile of normalized WMF averaged between $80^{\circ} \mathrm{S}$ and $90^{\circ} \mathrm{S}$ in July. In austral winter, the wind profile shear and curvature tend to more markedly reduce the SWMF in Antarctica (Fig. 3b) than in the NH midlatitudes in boreal winter (Fig. 3a). As shown in Fig. 9b, the SWMF in the NEW experiment is about 5\% weaker than that in OLD. Because of this large reduction, the NEW experiment produces a smaller WMF than OLD at all levels, which differs from what occurs in the NH midlatitudes in January (Fig. 9a). As a result, the OGWD in the upper troposphere over Antarctica is weakened rather than increased (Fig. 8f). 


\section{Conclusion and discussions}

Using the analytic formulae derived by TM06, based on a second-order WKB approximation, the KD05 OGWD parameterization scheme in the WRF model was revised by considering the effects of wind profile shear and curvature in the evaluation of the SWMF. Then the wind profile effects on the SWMF, and hence the vertical distribution of OGWD, were investigated via two sets of numerical experiments conducted using the GWRF model, namely, 1) experiment OLD using the original KD05 scheme, and 2) experiment NEW using the revised scheme. The reference-level height used in the KD05 scheme was adopted to estimate the corrections to the drag due to wind profile shear and curvature, as this is both consistent with the assumptions of the scheme and makes sense for corrections that were derived for inviscid conditions. For the OGWD scheme in the WRF model, the reference level appears to be the most reasonable choice, because OGWs are assumed to be generated at this level.

In January, the wind profile shear (i.e., WSHR term) causes notable negative corrections to the SWMF over Antarctica and between about $30^{\circ} \mathrm{S}$ and $60^{\circ} \mathrm{N}$, while the wind profile curvature (i.e., WCUR term) acts to enhance the SWMF everywhere except in the high latitudes of the NH. The net effect of wind profile shear and curvature is to increase (decrease) the SWMF in the SH (NH). In July, the behavior of the WSHR term is quite similar to that in January, although this term is increased in the high latitudes of the NH. On the contrary, the behavior of the WCUR term differs markedly from that in January, with the most remarkable differences taking place in the high latitudes of the SH, i.e., Antarctica. The WCUR term becomes negative in July, giving rise to a pronounced reduction of the SWMF there. The sign of the WCUR term is also reversed in the high latitudes of the NH (e.g., Greenland). The seasonal reversal of the WCUR term at high latitudes is due to the enhancement of near-surface winds in the winter 
season of each hemisphere. This enhancement increases the low-level vertical shear, leading to a reversal of the sign of the wind profile curvature. The ability of the wind profile curvature to, in practice (i.e. for real meteorological data), produce negative corrections to the SWMF over Antarctica is a new finding which contradicts the results of M09 and T19. This result of course relies on the type of drag parametrization used (which is different here from that adopted in the offline calculations of M09 and T19), on the simplifications assumed for the drag correction terms, and on the level used to evaluate these terms. This suggests that the behavior of these drag corrections is not as robust to the choice of that level as previously thought.

Changes in the SWMF are able to influence the vertical distribution of the OGWD. In January, the OGWD is more significant in the midlatitudes of the NH, at low levels below about $700 \mathrm{hPa}$, and in the upper troposphere and lower stratosphere. When wind profile effects are considered, the OGWD is increased in the upper troposphere but decreased in the lower troposphere and lower stratosphere. In July, the most notable OGWD is found in the lower and upper troposphere over Antarctica, with little OGWD in the NH. Under the influence of wind profile shear and curvature, the OGWD in the upper troposphere over Antarctica is reduced, which is different from what occurs in the NH midlatitudes in January. This is because the SWMF over Antarctica is more markedly affected by negative wind profile effects than in the NH midlatitudes.

To sum up, this study for the first time examines the behavior of the second-order WKB corrections to the SWMF due to wind profile effects derived by TM06, as well as their impacts on the vertical distribution of parameterized OGWD, in online simulations of a numerical model, which provide some useful insights into those effects. While the impact of these effects on the SWMF magnitude is relatively modest, their impact on the OGWD exerted in the overlying 
atmospheric column can be surprisingly strong at localized levels. This is because the magnitude of the SWMF determines the lowest level at which OGW breaking occurs, which in turn controls the depletion of the WMF that remains available to propagate to higher levels. Hence even a slight change in the SWMF can substantially modify the heights at which wave breaking takes place (and consequently flow deceleration is exerted).

To be compatible with the unidirectional wind assumption employed in the KD05 scheme, the present study had to adopt a reduced 2D version of the WKB corrections which accounts for the wind profile shear and curvature in the direction of low-level mean wind only. Extension of these corrections to their fully 3D version would be able to better capture wind profile effects on the SWMF. Moreover, sensitivities to the model vertical resolution and to the height where the SWMF and wind profile effects are evaluated were not addressed herein. Finally, this study only examined the impact of wind profile effects on the SWMF and on the WMF profiles. How these effects will influence the resolved atmospheric circulation is still unclear. This will be investigated using more comprehensive climate model simulations with the model top extended to higher levels (e.g., in the mesosphere) rather than at $10 \mathrm{hPa}$ (as in the present study), given that the impacts of OGWs are stronger in the middle atmosphere than in the troposphere. The effect of directional absorption of OGWs, addressed separately in X19, will be studied as well.

Acknowledgments. The authors would like to thank the anonymous reviewers for their comments. This study is mainly supported by the National Science Foundation of China (Grants 91837207, 41875068, 41505046, 41750965), and Fundamental Research Funds for the Central Universities (0207-14380046). The first author is also supported by the Beijing Climate Center (QHMS2019006). 


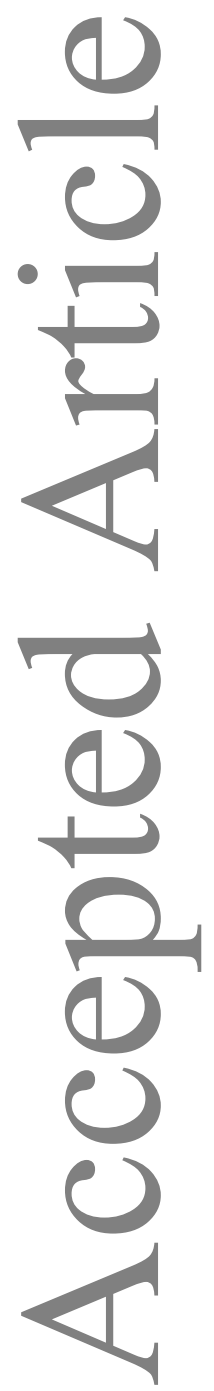

This article is protected by copyright. All rights reserved. 


\section{References}

Alexander, M. J., and coauthors, 2010: Recent developments in gravity-wave effects in climate models and the global distribution of gravity-wave momentum flux from observations and models. Quart. J. Roy. Meteor. Soc, 136, 1103-1124. https://doi.org/10.1002/qi.637.

Beljaars, A. C. M., 1994: The parameterization of surface fluxes in large-scale models under free convection. Quart. J. Roy. Meteor. Soc., 121, 255-270, https://doi.org/10.1002/qj.49712152203.

Cohen, N. Y., Edwin P. G., and B. Oliver, 2013: Compensation between resolved and unresolved wave driving in the stratosphere: Implications for downward control. J. Atmos. Sci., 70, 3780-3798, https://doi.org/10.1175/JAS-D-12-0346.1.

Grubis̄ić, V., and P. K. Smolarkiewicz, 1997: The effect of critical levels on 3D orographic flows: Linear regime. J. Atmos. Sci., 54, 1943-1960. https://doi.org/10.1175/15200469(1997)054<1943:TEOCLO >2.0.CO;2

Hong, S.-Y., J. Dudhia, and S. Chen, 2004: A revised approach to ice microphysical processes for the bulk parameterization of clouds and precipitation. Mon. Wea. Rev., 132, 103-120, https://doi.org/10.1175/1520-0493(2004)132<0103:ARATIM>2.0.CO;2.

Hong, S.- Y., Y. Noh, and J. Dudhia, 2006: A new vertical diffusion package with an explicit treatment of entrainment processes. Mon. Wea. Rev., 134, 2318-2341, https://doi.org/10.1175/MWR3199.1.

Hong, S.-Y., J. Choi, E.-C. Chang, H. Park, and Y.-J. Kim, 2008: Lower-tropospheric enhancement of gravity wave drag in a global spectral atmospheric forecast model. Wea. Forecasting, 23, 523-531, https://doi.org/10.1175/2007WAF2007030.1 
Iacono, M. J., J. S. Delamere, E. J. Mlawer, M. W. Shephard, S. A. Clough, and W. D. Collins, 2008: Radiative forcing by long-lived greenhouse gases: Calculations with the AER radiative transfer models. J. Geophys. Res., 113, D13103, https://doi.org/10.1029/2008JD009944

Kim, Y.-J., and A. Arakawa, 1995: Improvement of orographic gravity wave parameterization using a mesoscale gravity wave model. J. Atmos. Sci., 52, 18751902, https://doi.org/10.1175/1520-0469(1995)052<1875:IOOGWP>2.0.CO;2.

Kim, Y. -J., and J. D. Doyle, 2005: Extension of an orographic-drag parameterization scheme to incorporate orographic anisotropy and flow blocking, Quart. J. Roy. Meteor. Soc., 131, 1893-1921, https://doi.org/10.1256/qj.04.160.

Kim, Y. -J., S. D. Eckermann, and H. Y. Chun, 2003: An overview of the past, present and future of gravity-wave drag parametrization for numerical climate and weather prediction models. Atmos.-Ocean, 41, 65-98, https://doi.org/10.3137/ao.410105.

Lindzen, R. S., 1981: Turbulence and stress owing to gravity wave and tidal breakdown. $J$. Geophys. Res. Atmos., 86, 9707-9714, https://doi.org/10.1029/JC086iC10p09707.

Lott, F., and M. Miller, 1997: A new sub-grid orographic drag parameterization: Its formulation and testing, Quart. J. Roy. Meteor. Soc., 123, 101-127, https://doi.org/10.1002/qj.49712353704.

McFarlane, N. A., 1987: The effect of orographically excited gravity wave drag on the general circulation of the lower stratosphere and troposphere. J. Atmos. Sci., 44, 17751800, https://doi.org/10.1175/1520-0469(1987)044<1775:teooeg>2.0.co;2. 
Miranda, P. M. A., and I. N. James, 1992: Non-linear three-dimensional effects on the wave drag: Splitting flow and breaking waves. Quart. J. Roy. Meteor. Soc., 118, 1057-1081. https://doi.org/10.1002/qj.49711850803

Miranda, P. M. A., J. P. A. Martins, and M. A. C. Teixeira, 2009: Assessing wind profile effects on the global atmospheric torque. Quart. J. Roy. Meteor. Soc., 135, 807-814. https://doi.org/10.1002/qj.393

Moore, G. W. K., and I. A. Renfrew, 2005: Tip jets and barrier winds: A QuikSCAT climatology of high wind speed events around Greenland. J. Climate, 18, 3713-3725. https://doi.org/10.1175/JCLI3455.1

Oltmanns, M., F. Straneo, G. W. K. Moore, and S. H. Mernild, 2014: Strong downslope wind events in Ammassalik, southeast Greenland. J. Climate. 27, 977-993. https://doi.org/10.1175/JCLI-D-13-00067.1

Palmer, T. N., G. J. Shutts, and R. Swinbank, 1986: Alleviation of systematic westerly bias in general circulation and numerical weather prediction models through an orographic gravity wave drag parameterization. Quart. J. Roy. Meteor. Soc., 112, 1001-1039, https://doi.org/10.1002/qj.49711247406.

Parish, T. R., and D. H. Bromwich, 1991: Continental-scale simulation of the Antarctic katabatic wind regime. J. Climate, 4, 135-146. https://doi.org/10.1175/15200442(1991)004<0135:CSSOTA $>2.0 . \mathrm{CO} ; 2$

Phillips, D. S., 1984: Analytical surface pressure and drag for linear hydrostatic flow over threedimensional elliptical mountains, J. Atmos. Sci., 41, 1073-1084, https://doi.org/10.1175/1520-0469(1984)041,1073:ASPADF.2.0.CO;2. 
Richardson, M. I., A. D. Toigo, and C. E. Newman, 2007: Planet WRF: A general purpose, local to global numerical model for planetary atmosphere and climate dynamics, J. Geophys. Res. Atmos., 112, E09001, https://doi.org/10.1029/2006JE002825.

Sandu, I., P. Bechtold, A. Beljaars, A. Bozzo, F. Pithan, T. G. Shepherd, and A. Zadra, 2016: Impacts of parameterized orographic drag on the Northern Hemisphere winter circulation, J. Adv. Model. Earth Syst., 8, 196-211, https://doi.org/10.1002/2015MS000564.

Shutts, G., 1995: Gravity-wave drag parameterization over complex terrain: The effect of critical-level absorption in directional wind-shear. Quart. J. Roy. Meteor. Soc., 121, 1005-1021, https://doi.org/10.1002/qj.49712152504.

Sigmond, M., and T. G. Shepherd, 2014: Compensation between resolved wave driving and parameterized orographic gravity wave driving of the Brewer-Dobson circulation and its response to climate change. J. Climate, 27, 5601-5610, https://doi.org/10.1175/JCLI-D13-00644.1.

Smith, R. B., 1980. Linear theory of stratified flow past an isolated mountain. Tellus, 32, 348364. https://doi.org/10.1111/j.2153-3490.1980.tb00962.x

Teixeira, M. A. C., and P. M. A. Miranda, 2004: The effect of wind shear and curvature on the gravity wave drag produced by a ridge. J. Atmos. Sci., 61, 2638-2643. https://doi.org/10.1175/JAS3282.1

Teixeira, M. A. C., and P. M. A. Miranda, 2006: A linear model of gravity wave drag for hydrostatic sheared flow over elliptical mountains. Quart. J. Roy. Meteor. Soc., 132, 2439-2458, https://doi.org/10.1256/qj.05.220. 
Teixeira, M. A. C., Miranda, P. M. A., and Valente, M. A., 2004. An analytical model of mountain wave drag for wind profiles with shear and curvature. J. Atmos. Sci., 61, 10401054. https://doi.org/10.1175/1520-0469(2004)061<1040:AAMOMW>2.0.CO;2

Tewari, M., and coauthors, 2004: Implementation and verification of the unified NOAH land surface model in the WRF model. 20th conference on weather analysis and forecasting/16th conference on numerical weather prediction, pp. 11-15.

Turner, H. V., M. A. C. Teixeira, J. Methven, and S. B. Vosper, 2019: Sensitivity of the surface orographic gravity wave drag to vertical wind shear over Antarctica. Quart. J. Roy. Meteor. Soc., 145, 164-178. https://doi.org/10.1002/qj.3416

Xu, X., Y. Wang, and M. Xue, 2012: Momentum flux and flux divergence of gravity waves in directional shear flows over three-dimensional mountains, J. Atmos. Sci., 69, 3733-3744, https://doi.org/10.1175/JAS-D-12-044.1.

Xu, X., Shu, S., and Y. Wang, 2017a: Another look on the structure of mountain waves: A $\begin{array}{llll}\text { spectral } & \text { perspective. } & \text { Atmos. }\end{array}$ https://doi.org/10.1016/j.atmosres.2017.03.015.

Xu, X., Y. Wang, M. Xue, and K. Zhu, 2017b: Impacts of horizontal propagation of orographic gravity waves on the wave drag in the stratosphere and lower mesosphere. J. Geophy. Res., 122, 11301-11312, doi: 10.1002/2017jd027528.

Xu, X., Y. Tang, Y. Wang, and M. Xue, 2018: Directional absorption of mountain waves and its influence on the wave momentum transport in the Northern Hemisphere. J. Geophy. Res. Atmos., 123, 2640-2654, https://doi.org/10.1002/2017JD027968. 
Xu, X., M. Xue, M. A. C. Teixeira, J. Tang, and Y. Wang, 2019: Parameterization of directional absorption of orographic gravity waves and its impact on atmospheric general circulation simulated by Weather Research and Forecasting model. J. Atmos. Sci., 76, 3435-3453, https://doi.org/10.1175/JAS-D-18-0365.1

Zhang, C., Y. Wang, and K. Hamilton, 2011: Improved representation of boundary layer clouds over the southeast pacific in ARW-WRF using a modified Tiedtke cumulus parameterization scheme. Mon. Wea. Rev., 139, 3489-3513, https://doi.org/10.1175/MWR-D-10-05091.1. 

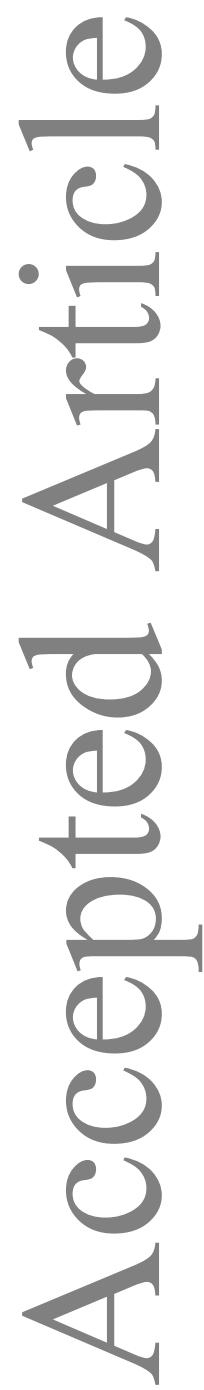

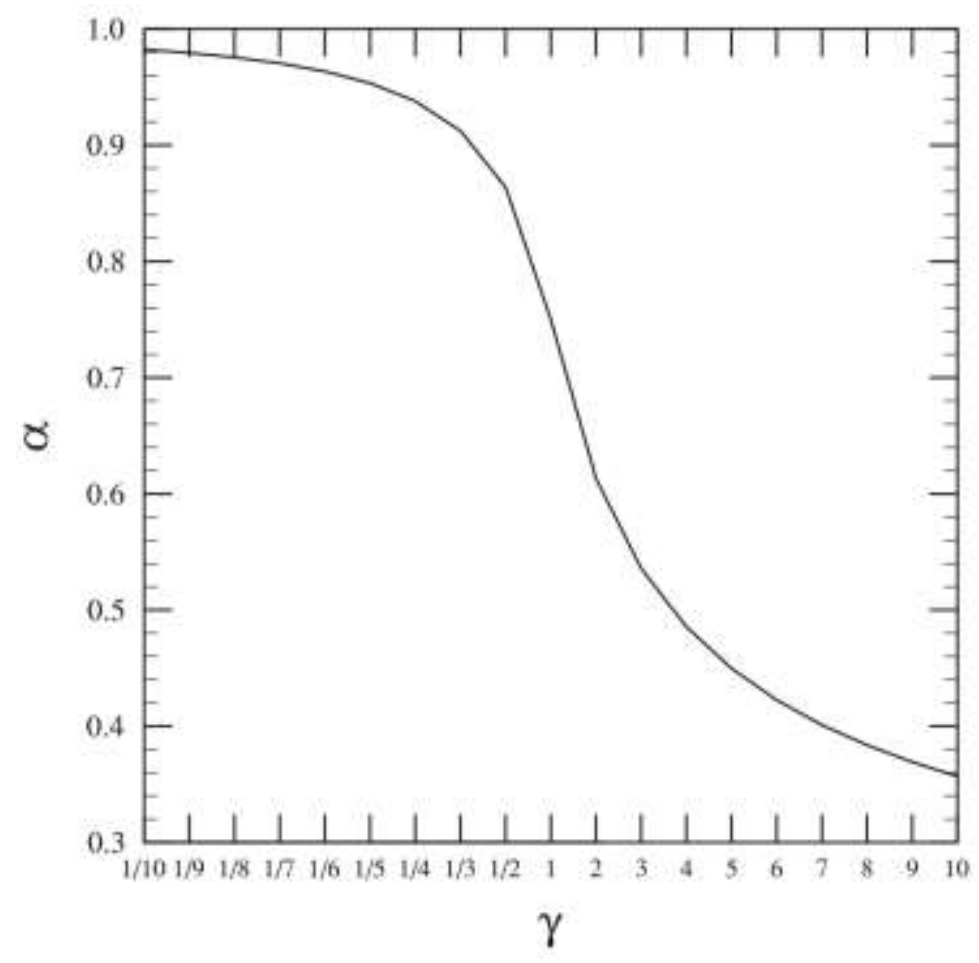

Fig. 1 Variation of $\alpha$ with $\gamma$ from $1 / 10$ to 10 . Note that the horizontal scale is only linear for $\gamma>1$. 

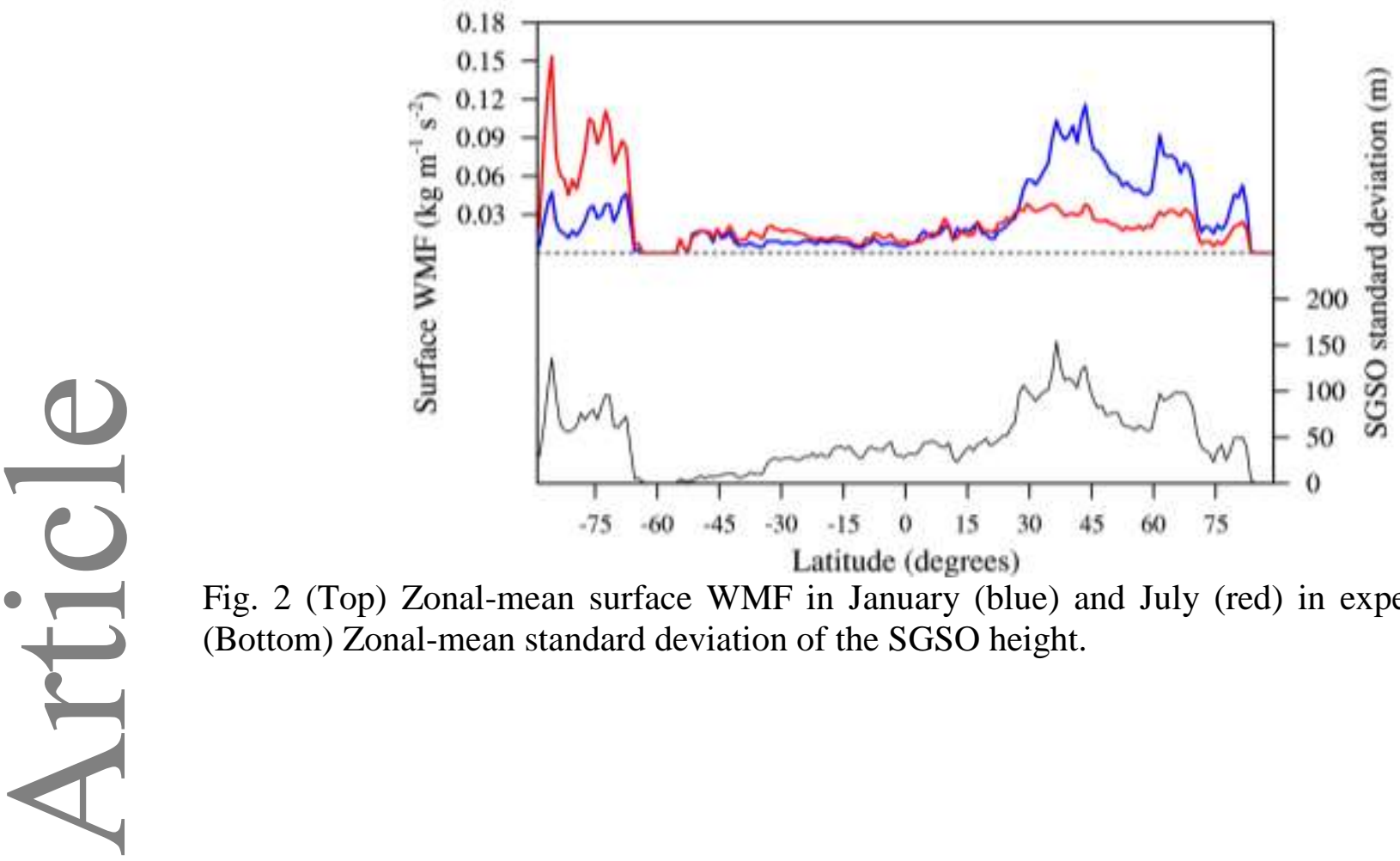

Fig. 2 (Top) Zonal-mean surface WMF in January (blue) and July (red) in experiment OLD. (Bottom) Zonal-mean standard deviation of the SGSO height. 

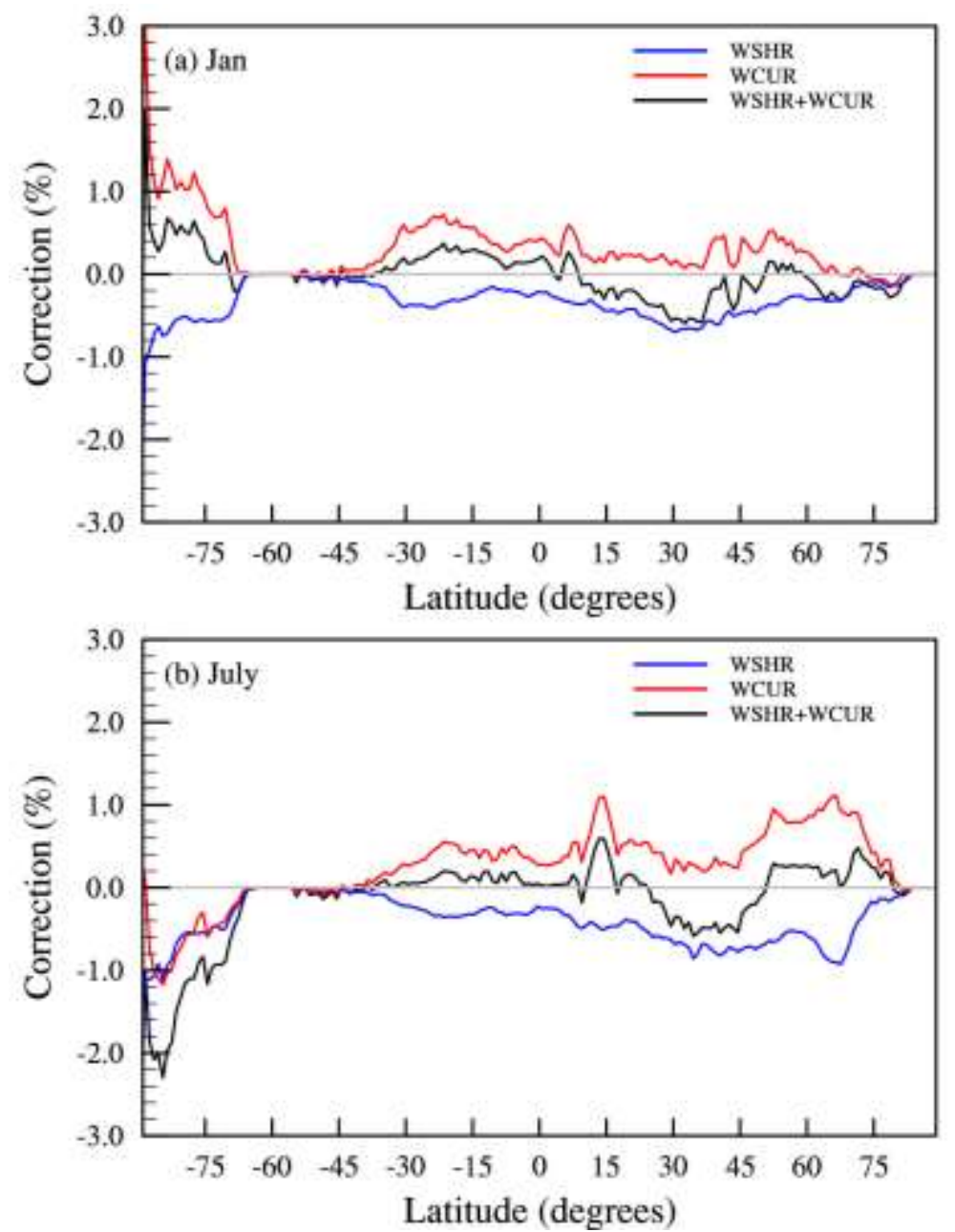

Fig. 3 Zonal-mean relative WKB drag corrections (units: \%) in (a) January and (b) July in experiment NEW. Blue and red lines are the WSHR and WCUR terms respectively, with the black line denoting the sum of the two (i.e., total WKB correction). 

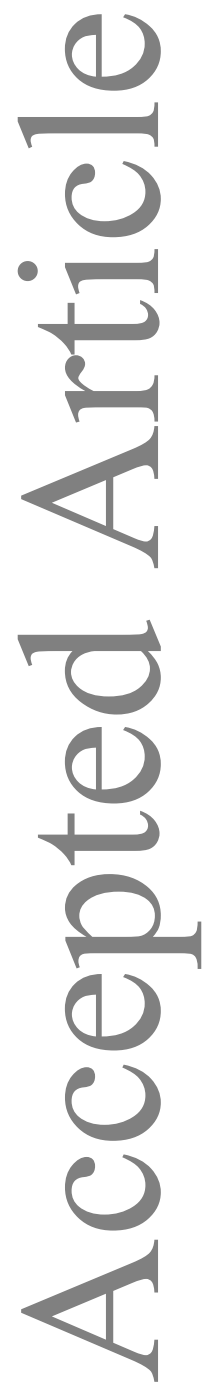
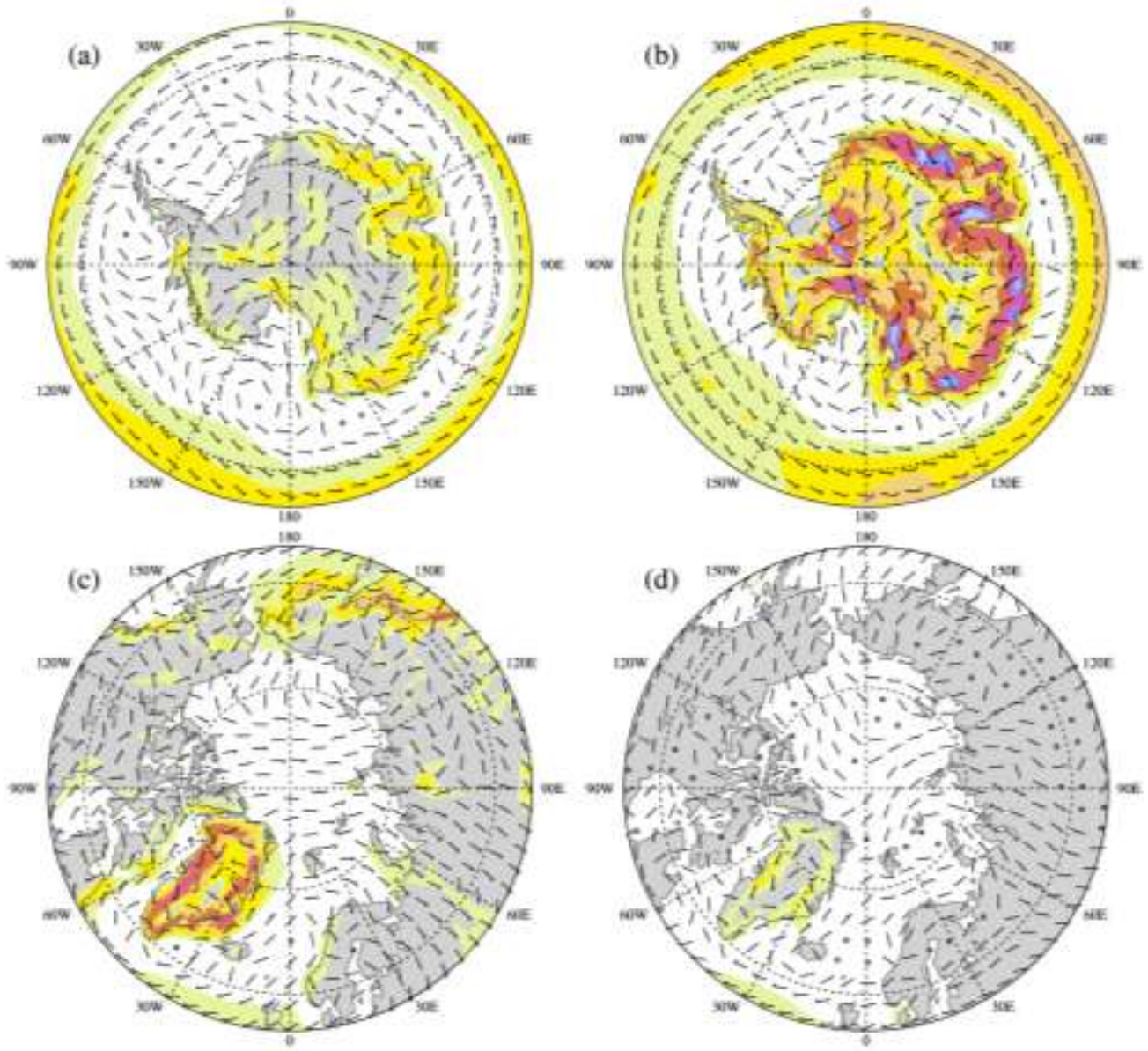

d)
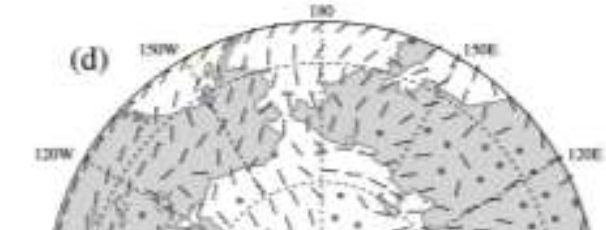

(1)
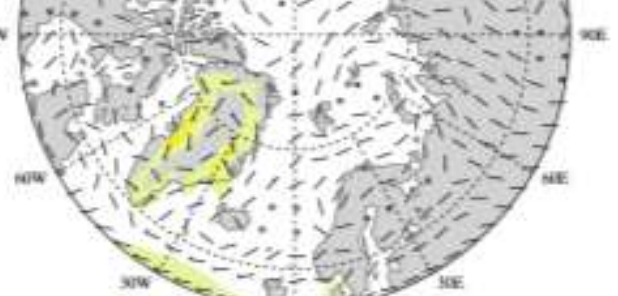

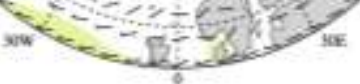
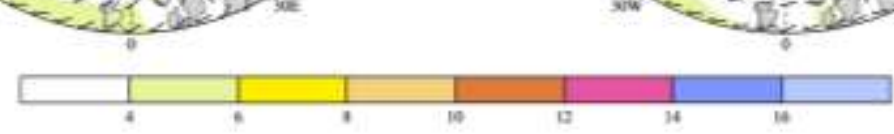

Fig. 5 Horizontal wind velocity (vectors) and wind speed (shading) (units: $\mathrm{m} \mathrm{s}^{-1}$ ) at the first model level in the polar regions in (a)(c) January and (b) (d) July in the NEW experiment. 

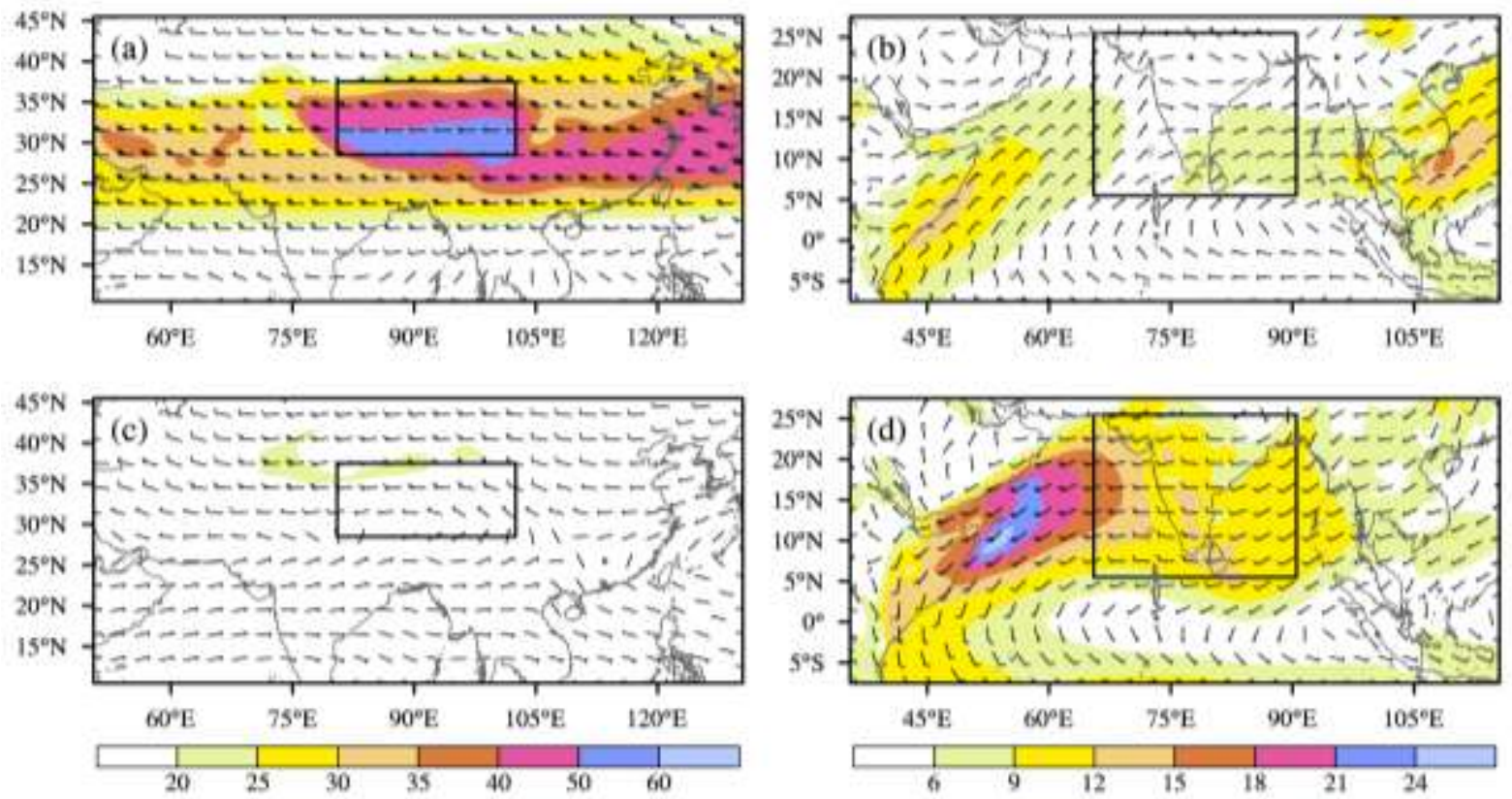

Fig. 7 Horizontal wind velocity (vectors) and wind speed (shading) (units: $\mathrm{m} \mathrm{s}^{-1}$ ) in (a)(b) January and (c)(d) July at $200 \mathrm{hPa}(\mathrm{a}, \mathrm{c})$ and $900 \mathrm{hPa}(\mathrm{b}, \mathrm{d})$ in experiment NEW. The boxes in the left (right) panel denote the regions from which the wind profiles in Fig. 6b (Fig. 6c) were extracted. 

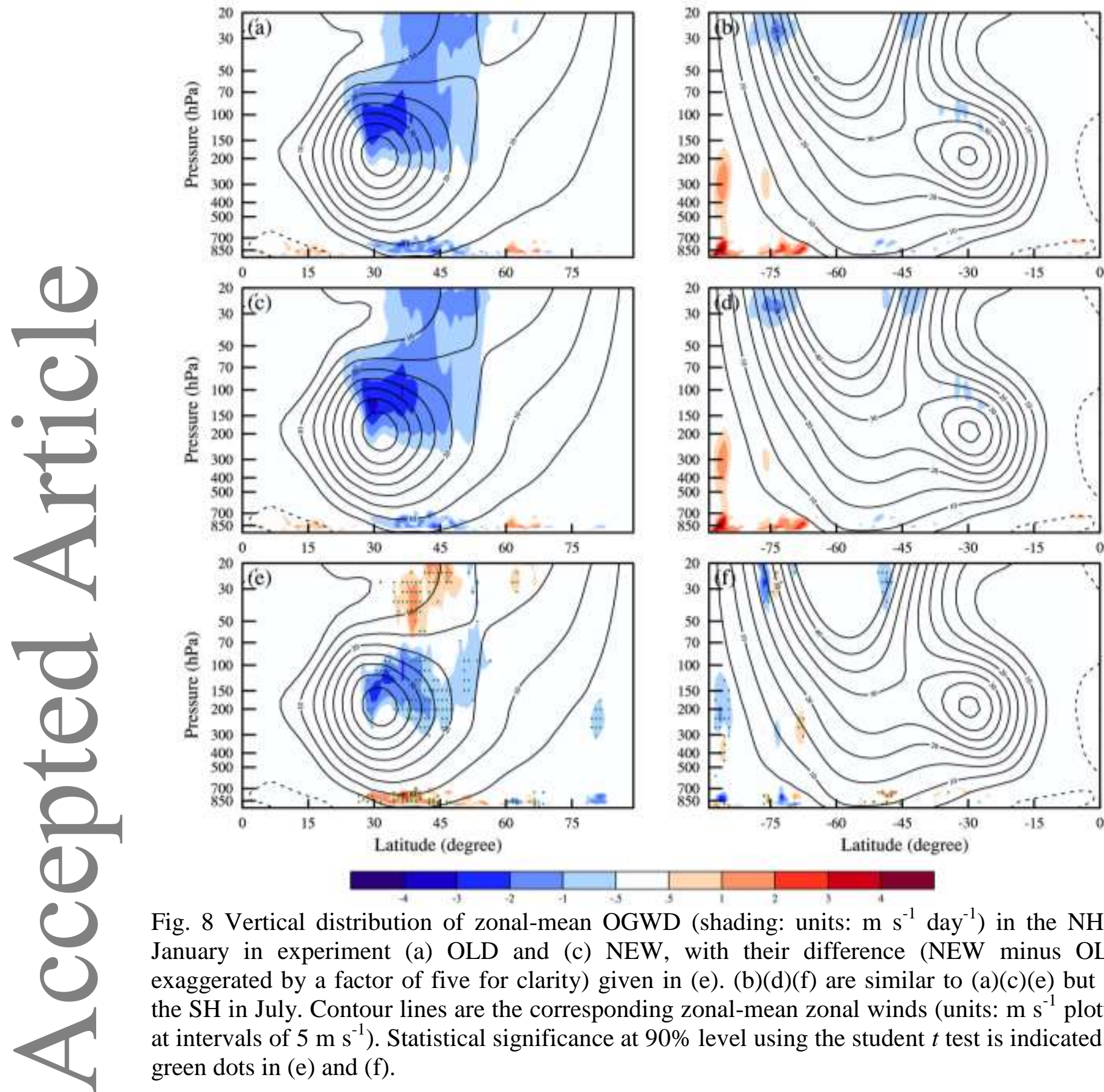

Fig. 8 Vertical distribution of zonal-mean OGWD (shading: units: $\mathrm{m} \mathrm{s}^{-1}$ day $^{-1}$ ) in the NH in January in experiment (a) OLD and (c) NEW, with their difference (NEW minus OLD, exaggerated by a factor of five for clarity) given in (e). (b)(d)(f) are similar to (a)(c)(e) but for the SH in July. Contour lines are the corresponding zonal-mean zonal winds (units: $\mathrm{m} \mathrm{s}^{-1}$ plotted at intervals of $\left.5 \mathrm{~m} \mathrm{~s}^{-1}\right)$. Statistical significance at $90 \%$ level using the student $t$ test is indicated by green dots in (e) and (f). 

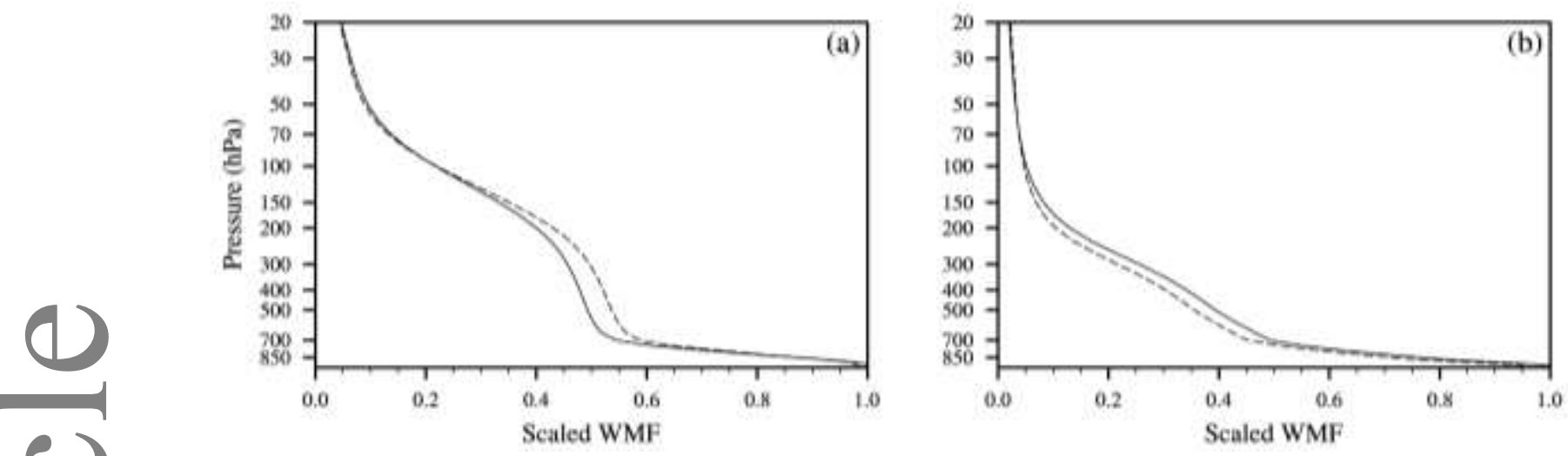

Fig. 9 (a) Profiles of the normalized WMF in experiment OLD (solid) and NEW (dashed) between $30^{\circ} \mathrm{N}$ and $50^{\circ} \mathrm{N}$ in January. The normalization is made with respect to the referencelevel WMF in OLD. (b) is similar to (a) but between $80^{\circ} \mathrm{S}$ and $90^{\circ} \mathrm{S}$ in July. 